Michael G. Ferrick, Norbert E. Yankielun

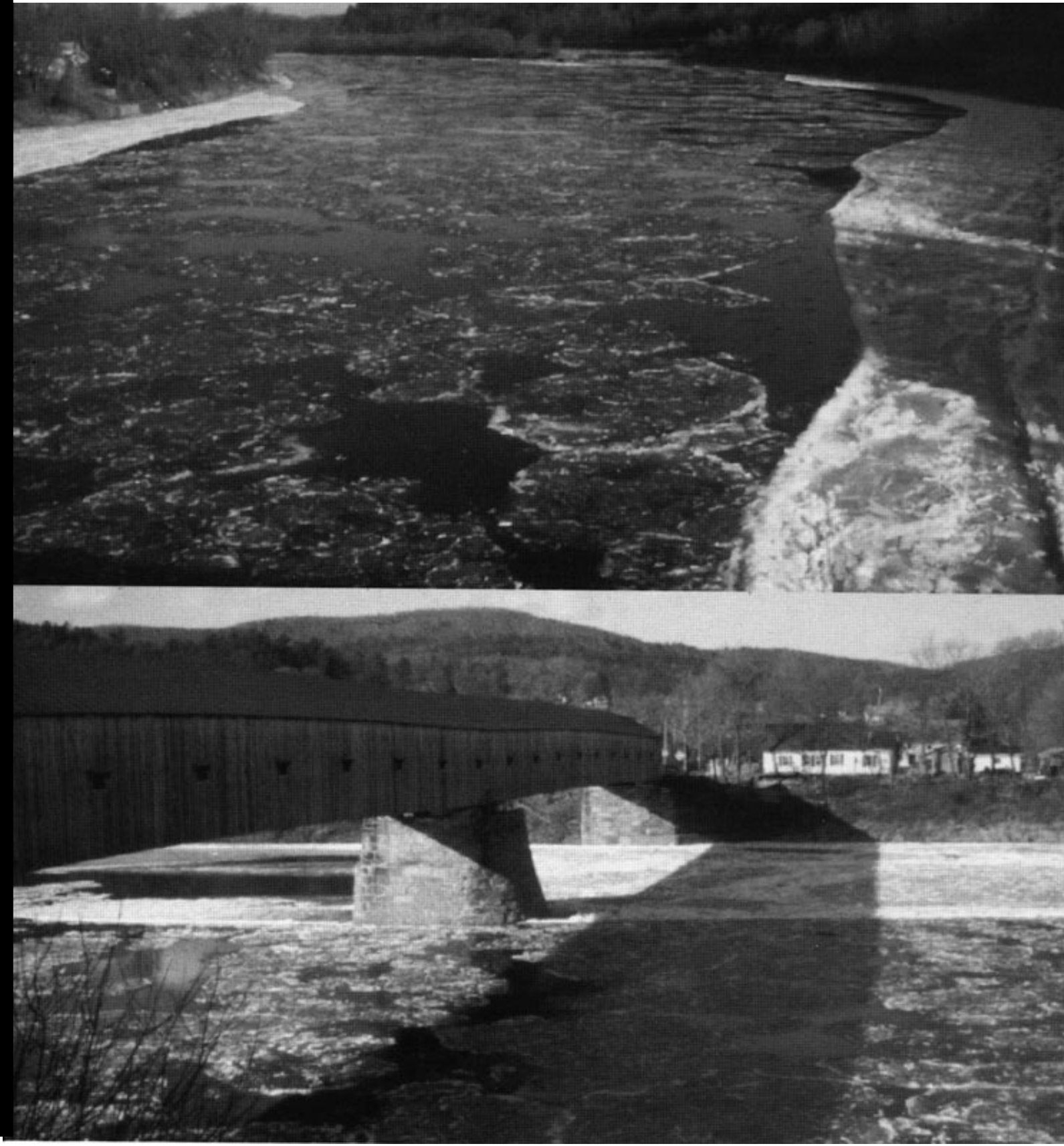




\begin{abstract}
River ice velocity measurements are fundamental to analyses of river ice dynamics. Ice velocity measurement with a continuous-wave Doppler radar system having real-time data acquisition and digital signal processing capability was evaluated during a river breakup and a frazil run on the Connecticut River. This system can be rapidly deployed, requires minimal operator interaction, will continuously acquire, process, store, and display ice velocity data and does not depend on visibility conditions. In parallel, video records of ice motion were obtained at the same location for later manual processing and comparison with the radar results. We describe the Doppler radar system and obtain bounding estimates of possible measurement errors. The principal error in Doppler ice velocity measurement is due to the beam width of the radar antenna, and an analytical method is developed to minimize this error. Measured ice velocities ranged from 1 to $2.5 \mathrm{~m} / \mathrm{s}$ during the river breakup and from 0.5 to $0.65 \mathrm{~m} / \mathrm{s}$ in the frazil run. Quantitative comparisons between the radar and video results show fundamental agreement between these measurement methods, and demonstrate that Doppler radar is an effective, efficient, and precise tool for obtaining river ice velocities over the full range of possible ice and velocity conditions.
\end{abstract}

Cover: Frazil ice run on the Connecticut River, 28 December 1993. Top: From the Cornish-Windsor Bridge radar site looking upstream. Bottom: From the left bank video site looking across the river. (Photos by M. Ferrick.)

For conversion of SI units to non-SI units of measurement consult Standard Practice for Use of the International System of Units (SI), ASTM Standard E38093, published by the American Society for Testing and Materials, 1916 Race St., Philadelphia, Pa. 19103. 


\section{CRREL Report 95-21}

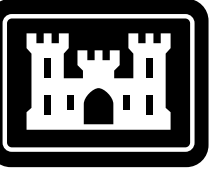

US Army Corps

of Engineers

Cold Regions Research \& Engineering Laboratory

\section{A Doppler Radar for Continuous Remote Measurement of River Ice Velocity}

Michael G. Ferrick, Norbert E. Yankielun

and David F. Nelson

November 1995 


\section{PREFACE}

This report was prepared by Michael G. Ferrick, Research Hydrologist, Snow and Ice Division; Norbert E. Yankielun, Electronic Engineer, Engineering Resources Branch; and David F. Nelson, Physical Science Aide, Snow and Ice Division, Research and Engineering Directorate, U.S. Army Cold Regions Research and Engineering Laboratory (CRREL), Hanover, New Hampshire.

Funding for the study was provided by work unit DT08-74-101, Combat Engineering System, and DA Project 4A762784AT42, Design, Construction, and Operations Technology for Cold Regions, Work Unit 001, Task CS, Winter Combat Engineering.

This report was technically reviewed by Steven Arcone and James Lever of CRREL. The authors wish to thank Nicholas Goodman (data processing), Patricia Weyrick (field work), William Bates (illustration), Maria Bergstad (editing), and Donna Valliere (final report preparation).

The contents of this report are not to be used for advertising or promotional purposes. Citation of brand names does not constitute an official endorsement or approval of the use of such commercial products. 


\section{CONTENTS}

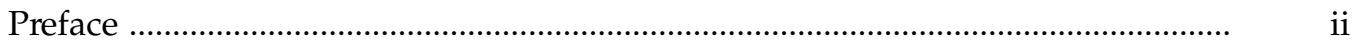

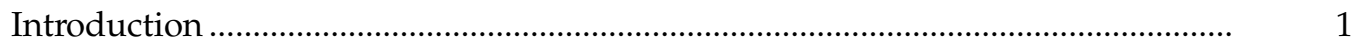

System description ................................................................................................

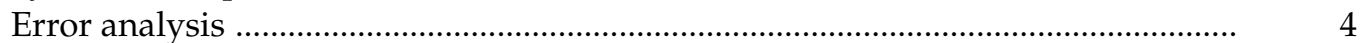

Velocity from a Doppler frequency band and a video record .................................. 5

Ice breakup_March 1993 ....................................................................................... 7

Frazil ice run-December 1993 ........................................................................ 9

Conclusions ....................................................................................................... 11

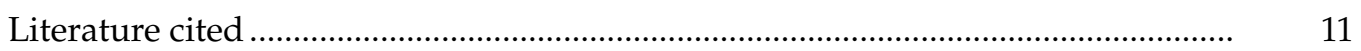

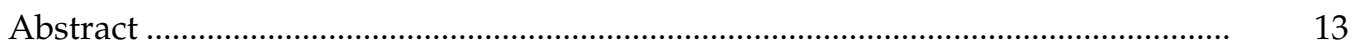

\section{ILLUSTRATIONS}

Figure

1. The effect of surface roughness on radar backscatter, and defining terms and parameters ........................................................................................ 2

2. The 3-dB beam width of a radar antenna ....................................................... 3

3. Fundamental components of the Doppler radar system with an expanded

view of the front-end .....................................................................................

4. Power spectra of single and multiple scans ..........................................................

5. Relationship between the velocity ratio and $\theta_{\mathrm{a}}$ for both the near and far edges of the beam width and a range of $\beta$ values .................................... 5

6. Example that quantifies the near- and far-edge velocity ratio with the boresight velocity

3

4

7. Data band of raw Doppler velocities and peak returns for the ice breakup event

8. Calculated $\theta_{\mathrm{a}}$ as a function of time for the raw and peak radar data records for the breakup event

9. Ice breakup boresight velocities and their normalized difference obtained

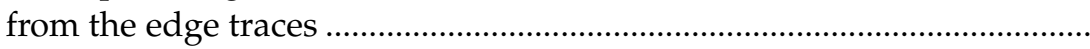

10. Ice velocity data, best polynomial fit, and normalized difference between

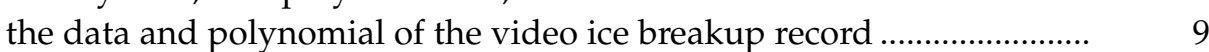

11. Comparison of ice velocity results for breakup ....................................................

12. Video and radar data, best polynomial fits, and normalized difference between the data and corresponding polynomial for the frazil ice run. 10

13. The part of the radar velocity record for breakup with dispersed ice floes

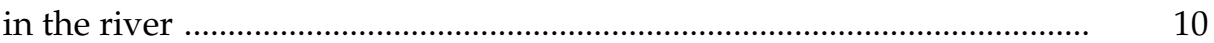

14. Comparison of ice velocity results for the frazil run ........................................ 11

\section{TABLE}

Table

1. Doppler system configurations ........................................................................... 



\title{
A Doppler Radar for Continuous Remote Measurement of River Ice Velocity
}

\author{
MICHAEL G. FERRICK, NORBERT E. YANKIELUN, AND DAVID F. NELSON
}

\section{INTRODUCTION}

Accurate ice velocity measurement during river breakup in spring is needed for analysis of river and ice dynamics and for flood hazard or water resource assessment. Ice velocity measurements presented by Ferrick et al. (1993) demonstrated the spatial and temporal variability of the motion during a dynamic breakup of the Connecticut River. Similar though generally slower and more gradually variable motion occurs during the freeze-up of a river. Ferrick et al. (1992) described the acquisition of ice velocity data by locating a length reference on the ice, recording the ice motion on videotape, developing a computer-generated reference grid that is dubbed over the videotape, and timing the motion of individual floes through the grid. The shortcomings of this method are that it is laborious and it requires visual observation of the ice, which can be precluded by fog and darkness. Ice scour of the bed and banks frequently prevents the use of measurement methods that require sensor and cable placement in the river. Radar systems have been applied to hydrological investigations, including the measurement and mapping of ice thickness on rivers and lakes (Arcone and Delaney 1987, Arcone 1991, Yankielun et al. 1992, 1993) and the continuous monitoring of river stage (Yankielun and Ferrick 1993). Doppler radar techniques for velocity measurement are well established (Barton 1964, Skolnik 1980) and provide a remotely mounted, readily installed, continuously recording alternative for ice velocity measurement that is not affected by light, fog, or ice motion conditions.

A continuous wave (CW) Doppler radar with real-time data acquisition and digital signal processing capability was mounted on the Cornish (N.H.)-Windsor (Vt.) bridge over the Connecticut
River during the March 1993 ice breakup and again in December 1993 during a frazil ice run prior to ice cover formation. Ice velocity data were continuously acquired, processed, displayed, and stored. The system can be transported in a vehicle and rapidly redeployed to permit data acquisition at a number of locations during a single event with minimal operator interaction. Simultaneous ice velocity data were obtained at the same site with video techniques during both of these events.

In this paper we describe the Doppler radar system, analyze the contributions to measurement error inherent in the system, determine error bounds, and develop data processing methods to minimize the error in the velocity measurement. Quantitative comparisons of measured ice velocity are made between the radar and video techniques for both the breakup and frazil events. Methods for enhancing the accuracy of Doppler radar ice velocity measurement and its ease of use follow from the analysis.

\section{SYSTEM DESCRIPTION}

The primary requirement for a successful radar measurement is that the target provide sufficient backscatter of the incoming wave. If the surface area illuminated by the radar were perfectly smooth, the incident energy would be reflected away from the radar antenna. However, the inherent roughness of frazil, sheet, and rubble ice provides backscatter towards the antenna (Fig. 1). The fundamental relationship between transmitted and received power of a radar signal traveling through free space was described in Skolnik (1980). Lewis et al. (1987) discussed the specific problem of radar detection of floating ice 

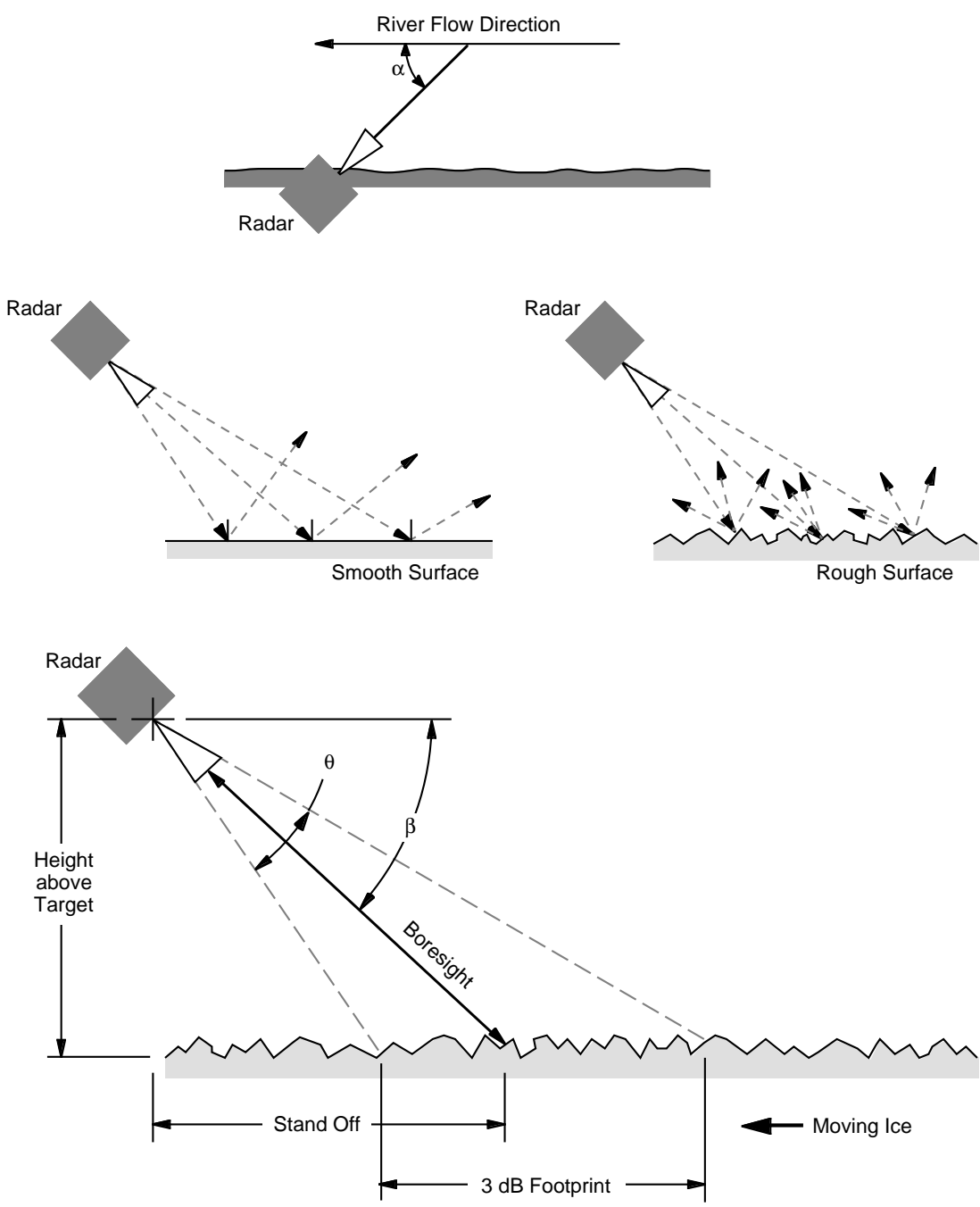

Figure 1. The effect of surface roughness on radar backscatter, and defining terms and parameters.

masses on large bodies of water. The backscattered power received $P_{\mathrm{r}}(\mathrm{W})$ is related to system and target parameters as

$$
P_{\mathrm{r}}=\frac{P_{\mathrm{t}} G^{2} \lambda^{2} A \sigma_{\mathrm{o}}}{(4 \pi)^{3} R^{4} L},
$$

where $P_{\mathrm{t}}=$ power transmitted $(\mathrm{W})$

$G=$ antenna gain

$\lambda=$ radar wavelength $(\mathrm{m})$

$A=$ area illuminated by the radar $\left(\mathrm{m}^{2}\right)$

$R=$ range to the target $(\mathrm{m})$

$\sigma_{\mathrm{o}}=$ normalized cross section of the target

$L=$ system losses
An ideal reflector returns all incident energy back to the source, corresponding to a $\sigma_{0}$ of 1 . The radar cross section of a target is defined as the normalized area of an ideal reflector that would return the same signal strength as the target. Several factors affect the radar cross section of a given target, including transmitted wavelength, target geometry, aspect, and reflectivity. A calibrated radar system is necessary to measure $\sigma_{\mathrm{o}}$ for various target conditions. Moving river ice presents an inhomogeneous target with complex and variable geometry, and the radar cross section can vary widely.

An additional requirement for Doppler veloc- 
ity measurement is that the frequency shift obtained must be resolvable by the radar system. In a CW Doppler system a single-frequency RF carrier is transmitted toward the target at an oblique angle (Fig. 1). When the target is moving, the backscattered signal exhibits an apparent shift from the transmitted carrier frequency-higher if movement is toward the radar and lower if it is away from it. A low-level sample of the transmitted carrier frequency $f_{\mathrm{s}}$ is used as a reference and mixed with the backscattered signal received. The mixing process results in four frequencies: the reference signal, the backscattered signal, and the sum and difference of these frequencies. The difference frequency resulting from the mixing is the Doppler frequency $f_{\mathrm{d}}$ proportional to the velocity of the target. The velocity $v(\mathrm{~m} / \mathrm{s})$ of a moving target is obtained as (Roddy 1984)

$$
v=\frac{\lambda f_{\mathrm{d}}}{2 \cos \alpha \cos \beta}
$$

where $\lambda=$ wavelength $(\mathrm{m})$ of the RF source

$\alpha=$ horizontal off-stream angle as shown in Figure 1.

$\beta=$ vertical look-angle measured downward from the horizontal

The wavelength and frequency of the source are related as $\lambda=c / f_{\mathrm{s}}$, where $c$ is the speed of light in a vacuum $\left(3 \times 10^{8} \mathrm{~m} / \mathrm{s}\right)$. The power transmitted by the radar is not localized at the point on the target surface aligned with the center of the antenna boresight. Instead, it is distributed over an area on the surface, with the incident power diminishing with distance from the boresight. The 3 -dB beam width shown in Figure 1 is defined as the angular width of the radar beam at the halfpower points, as illustrated in Figure 2.

The Doppler radar implementation used for these experiments (Fig. 3) includes a radar frontend and a data acquisition and processing computer. The radar front-end system (expanded in Fig. 3) consists of a standard gain horn antenna that is connected via a circulator to a single-frequency, continuous-wave microwave source and a single-ended diode mixer. The circulator is a ferromagnetic device that directionally commutates power on a sequential port-to-port basis and permits simultaneous noninterfering transmission and reception of the radar signal using a single antenna. Ideally, all power entering port 1 is transmitted to port 2, power entering port 2 is transmitted to port 3 , and power entering port 3 is transmitted to port 1. Port-to-port isolation in the

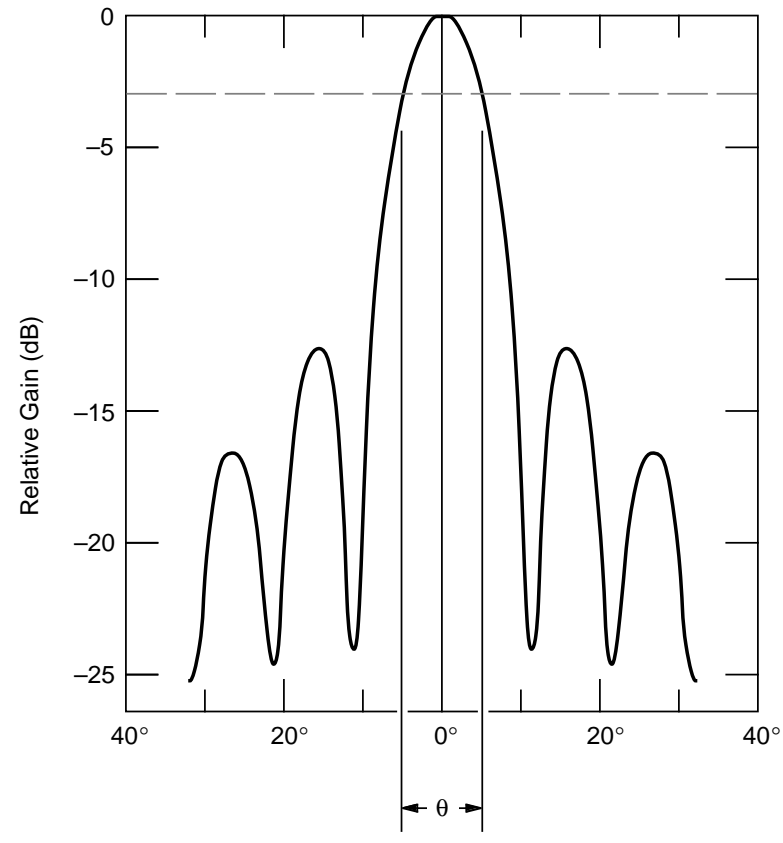

Figure 2. The 3-dB beam width of a radar antenna.

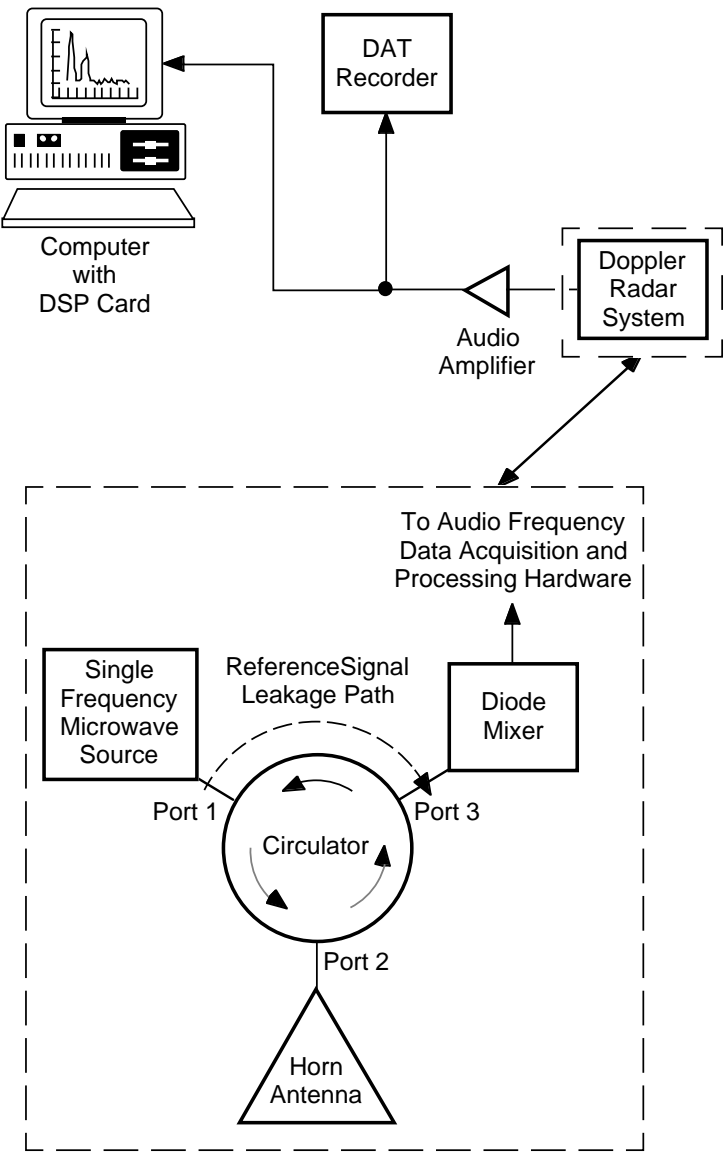

Figure 3. Fundamental components of the Doppler radar system with an expanded view of the front-end. 
reverse direction is not complete, with a typical power "leakage" of about $-20 \mathrm{~dB}$. The leakage between ports 1 and 3 is used as the reference signal for the mixer. The front-end assembly is mounted on a tripod that can be accurately positioned with an inclinometer to within $\pm 1^{\circ}$ in the vertical plane. Horizontally, the radar is visually aimed upstream into the flow, and alignment is adjusted during the ice motion by manually panning the antenna until the radar response indicates a velocity maximum. Data acquisition and display were performed with a 33-MHz 80386 DOS computer system. A DSP card acquires 16-bit data and displays the digital signal of the velocity spectrum in real time. Data were recorded continuously on one track of a four-track digital audio tape (DAT) recorder for later playback, processing, and analysis. The DAT recorder was also used to record concurrent river stage data from a millimeter-wave FM-CW radar (Yankielun and Ferrick 1993), event timing, and a voice channel for a descriptive narrative.

After completion of a survey, the raw Doppler data were processed and displayed. Each radar scan was digitized to provide 1024 time series samples, transformed into a power spectrum and processed with a Hanning window to suppress the effect of spectral sidelobes that could mask lower-level signals. The processed power spectrum can be displayed in either a single-scan format or as a continuous series of scans in spectrographic form (Fig. 4). In a spectrogram, discrete

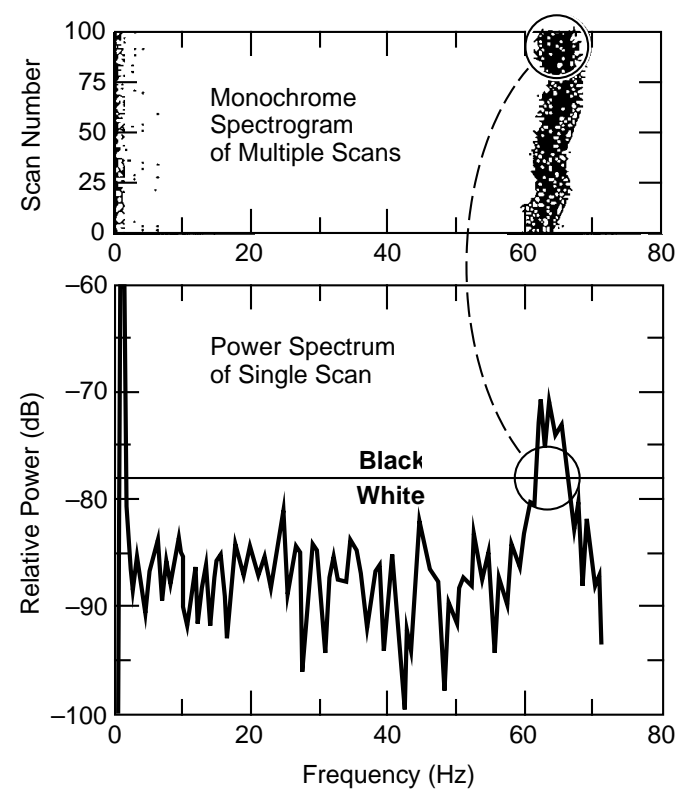

Figure 4. Power spectra of single and multiple scans that indicate the relationship between the amplitude threshold setting and the bandwidth of Doppler frequencies. signal magnitude quanta are represented by a range of color or gray scale. With 16-shade gray scale graphics, the maximum signal magnitudes appear black, and intermediate levels appear as lighter shades of gray. Below a preset magnitude threshold all is shown as white. The levels can be set in the DSP software to display the Doppler frequency clearly. A multicolor spectrographic display provides a 256-shade color gradient that significantly improves graphical resolution.

\section{ERROR ANALYSIS}

To assess the capability of Doppler radar to measure ice velocity we must identify and quantify the sources of error inherent in the method and minimize these errors for minimum total error. It would be useful to combine the individual errors and obtain an upper bound on the total error. We take $v$ in eq 2 as the dependent variable, and write the total differential $d v$ as

$$
d v=\frac{\partial v}{\partial \beta} d \beta+\frac{\partial v}{\partial \alpha} d \alpha+\frac{\partial v}{\partial \lambda} d \lambda+\frac{\partial v}{\partial f_{\mathrm{d}}} d f_{\mathrm{d}} .
$$

An upper bound on the total error is obtained as the sum of the absolute values of the terms in eq 3 , when each term represents an individual upper bound. The differentials of the independent variables will be replaced by finite quantities that we assume are small enough for eq 3 to provide an accurate estimate of each component of error.

The vertical angle and horizontal angle must be known precisely to obtain an accurate velocity measurement. The partial derivatives of velocity in eq 2 with respect to $\alpha$ and $\beta$ have the same form:

$$
\frac{\partial v}{\partial \beta}=v \tan \beta ; \frac{\partial v}{\partial \alpha}=v \tan \alpha .
$$

When maximum error is being evaluated, the values of $\alpha$ and $\beta$ in eq 4 should be the most probable angle plus the estimate of angular error. The wavelength of the CW RF source is known and should be precise and stable for accurate measurement. Wavelength error is the difference between the actual and the measured radar source carrier wavelength. The quantized nature of digital sampling is a source of error in the Doppler frequency. The partial derivative of velocity in eq 2 with respect to wavelength $\lambda$ and Doppler frequency $f_{\mathrm{d}}$ have the same form:

$$
\frac{\partial v}{\partial \lambda}=\frac{v}{\lambda} ; \frac{\partial v}{\partial f_{\mathrm{d}}}=\frac{v}{f_{\mathrm{d}}} .
$$


We can now rewrite eq 3 as an upper-bound percentage error in velocity, expressing each of the differentials as finite errors $\Delta$ :

$$
\left|\frac{\Delta v}{v}\right|=|\tan \beta \cdot \Delta \beta|+|\tan \alpha \cdot \Delta \alpha|+\left|\frac{\Delta \lambda}{\lambda}\right|+\left|\frac{\Delta f_{\mathrm{d}}}{f_{\mathrm{d}}}\right| .
$$

Our vertical angle measurement by inclinometer of $25^{\circ}$ was accurate to within $\pm 2^{\circ}$, and the horizontal angle alignment to the maximum velocity at $0^{\circ}$ was accurate to about $\pm 5^{\circ}$. The upper-bound percentage error contributions of these terms are then 0.018 and 0.0076 , respectively. A source frequency of $5 \mathrm{GHz}$ and an upper bound frequency error of $100 \mathrm{MHz}$ yield a percentage error in $\lambda$ of 0.02 . The percentage error in $f_{\mathrm{d}}$ is

$$
\left|\frac{\Delta f_{\mathrm{d}}}{f_{\mathrm{d}}}\right|=\frac{1}{N}
$$

where $N$ is the number of samples acquired and processed per second for each Doppler frequency determination. In our system, the sampling frequency $N$ was $1024 \mathrm{~Hz}$, corresponding to a negligible digital sampling error of less than 0.001 . The sum of the absolute values of the upperbound error estimates in eq 6 yields $|\Delta v / v|$ equal to 0.047 .

The beam width of the radar antenna introduces another potential error, in addition to those given by eq 6 . The antenna beam width corresponds to an area on the surface of the ice that is illuminated by the radar and returns backscatter to the antenna. Because $f_{\mathrm{d}}$ is angle-dependent, a band of Doppler frequencies represents the backscatter from across the illuminated area. The near edge of the beam corresponds to the largest vertical angle and the upper-bound error. Following the approach taken above, we obtain an upperbound estimate of this error by replacing $\beta$ by $\beta+$ $\theta / 2$ in eq 2 and taking the partial derivative of velocity with respect to $\theta / 2$ :

$$
\left(\frac{\theta}{2}\right) \frac{\partial v}{\partial(\theta / 2)}=v \tan \left(\beta+\frac{\theta}{2}\right)\left(\frac{\theta}{2}\right) .
$$

When is $\theta$ greater than $10^{\circ}$, the beam-width error given by eq 8 is potentially larger than the sum of the upper-bound errors in eq 6 .

\section{VELOCITY FROM A DOPPLER FREQUENCY BAND AND A VIDEO RECORD}

Systems with large beam width antennas require additional data analysis to obtain an accu- rate velocity from the Doppler frequency band at each selected time throughout the record. If the actual vertical angle $\beta$ representing any point in the frequency band were known, the velocity at the corresponding time could be obtained from eq 2 . However, these angles are not generally known. The apparent far and near edge returns are the most readily identifiable locations on the frequency band. The width of this band depends on the antenna beam width and the threshold setting on the power spectrum of the backscattered signal. Our initial step in data reduction is to replace the frequency scale of the data band by a velocity scale using eq 2 with the boresight angle as $\beta$. The center of this band is the approximate ice velocity, and it can be obtained immediately. For more precise work during postprocessing, the apparent far and near edge velocities $v_{+}$and $v_{-}$, corresponding to the upper and lower edges of the band, are related to each other and the desired velocity $v$ as

$$
v=\frac{\cos \beta}{\cos \left(\beta-\frac{\theta_{\mathrm{a}}}{2}\right)} v_{+}=\frac{\cos \beta}{\cos \left(\beta+\frac{\theta_{\mathrm{a}}}{2}\right)} v_{-},
$$

where $\theta_{\mathrm{a}}$ is an apparent beam-width angle. The velocity $v$ corresponding to the antenna boresight is bounded above by $v_{+}$and below by $v_{-}$. We obtain the difference between the edge velocities as a percentage of the velocity $v$ from eq 9 as

$$
\frac{v_{+}-v_{-}}{v}=\frac{\cos \left(\beta-\frac{\theta_{\mathrm{a}}}{2}\right)-\cos \left(\beta+\frac{\theta_{\mathrm{a}}}{2}\right)}{\cos \beta} .
$$

The near and far edge velocity ratios $v_{-} / v$ and $v_{+} /$ $v$ are plotted in Figure 5 as a function of $\theta_{a}$ for a range of boresight angles $\beta$. The potential beam-

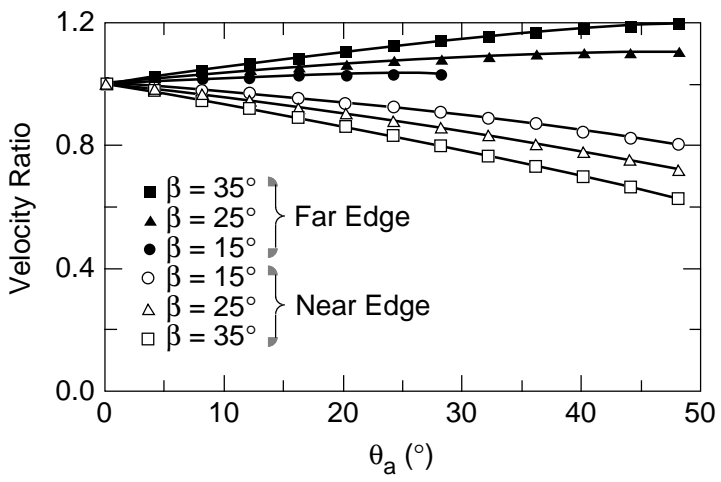

Figure 5. Relationship between the velocity ratio and $\theta_{a}$ for both the near and far edges of the beam width and a range of $\beta$ values. 


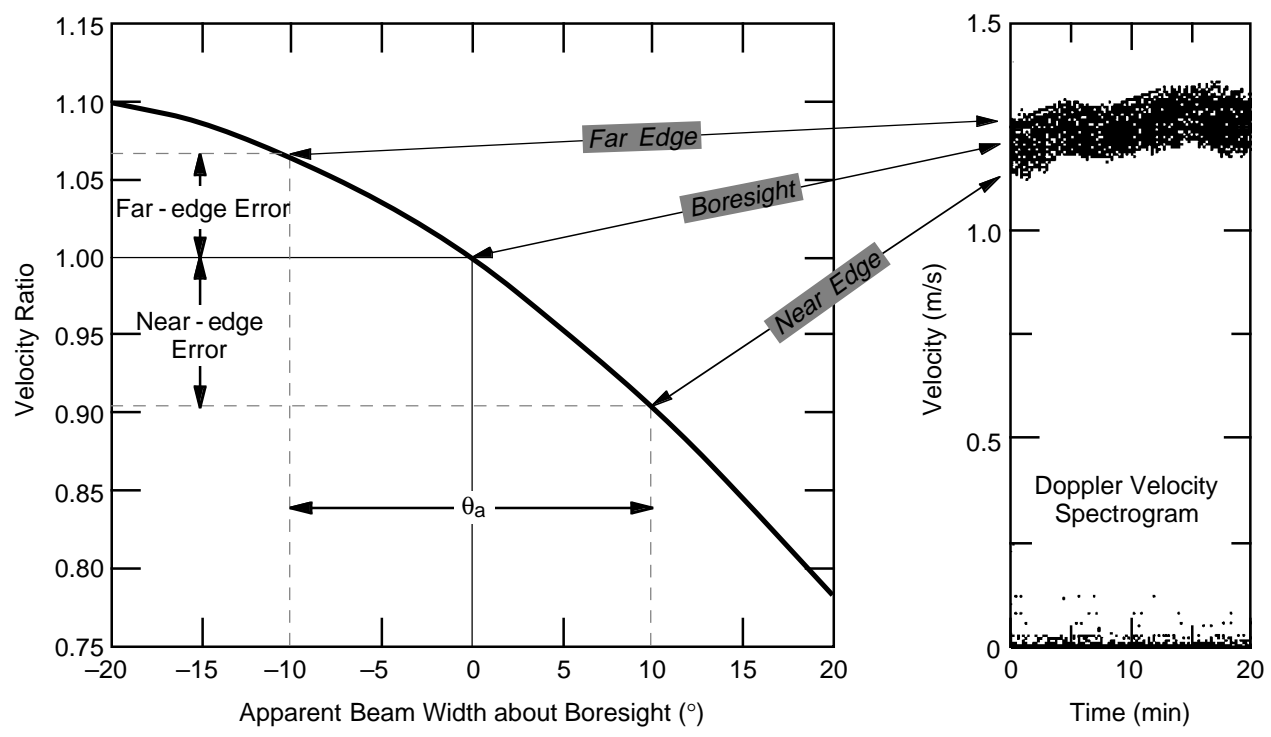

Figure 6. Example that quantifies the near-and far-edge velocity ratio with the boresight velocity for a specific case, $\beta=25^{\circ}$ and $\theta_{a}=20^{\circ}$, and relates them to specific locations on the spectrogram.

width errors increase significantly with $\theta_{\mathrm{a}}$ for all boresight angles and increase with $\beta$ for all beam widths. A sample Doppler velocity spectrogram is related to the velocity ratio relationship for $\beta=$ $25^{\circ}$ and $\theta_{a}=20^{\circ}$ in Figure 6.

Manipulating the relationship between the edge velocities in eq 9 we solve for $\theta_{a}$ as

$$
\theta_{\mathrm{a}}=2 \tan ^{-1}\left[\frac{\frac{v_{+}}{v_{-}}-1}{\left(\frac{v_{+}}{v_{-}}+1\right) \tan \beta}\right] \text {. }
$$

If both upper and lower bounding traces are drawn consistently, $\theta_{\mathrm{a}}$ should vary randomly within a narrow range. Velocity estimates $v_{1}$ and $v_{2}$ are obtained with the mean $\theta_{\mathrm{a}}$ as

$$
v_{1}=\frac{\cos \beta}{\cos \left(\beta-\frac{\bar{\theta}_{\mathrm{a}}}{2}\right)} v_{+} ; \quad v_{2}=\frac{\cos \beta}{\cos \left(\beta+\frac{\bar{\theta}_{\mathrm{a}}}{2}\right)} v_{-}
$$

Finally, the measured Doppler velocity $v$, representing the bulk ice velocity within the radar footprint, is taken as the average of $v_{1}$ and $v_{2}$.

A reference grid for video ice velocity measurement was established by placing visual targets on the winter ice cover at known spacing. The video records of the breakup and frazil run events were obtained by timing ice floes through this grid. As in previous work, we assume that the measured data contain a slowly varying com- ponent that provides the global variation of ice velocity with time and a comparatively rapid variation of small amplitude that represents measurement error or noise in the data. Separating these components requires the development of a function that contains most of the information in the data and little of the error or noise. The video data were fitted with orthogonal polynomials of increasing order until the maximum differences ceased to diminish and the time series of these differences appeared random. The polynomial, as a single-valued function of time, permits quantitative comparison of the radar and video records.

Prowse and Demuth (1991) emphasized the importance of a viewing position with large freeboard and accurate vertical angle measurement to obtain accurate ice velocity measurement with a related optical method. The water levels during breakup were much higher than those during target setup, occupying $30 \%$ of the setup freeboard. The resulting change in vertical angle from the camera to all points on the ice caused distortion of the original grid by length-scale changes that depend on position in the cross section of the river. The open water during the frazil ice run was at a level comparable to that of the winter ice cover. The data from both events were obtained along a single streamline in the river, providing consistent results that can be corrected for a change in length scale. The velocity data obtained from the original grid $v_{\text {grid }}$ are related to the actual velocity $v$ as 


$$
v_{\text {grid }}=\frac{X_{\text {grid }}}{\Delta t}=\frac{X+\Delta X}{\Delta t}=v+\Delta v
$$

where $X$ is the actual length scale, $\Delta t$ is the transit time of a floe over $X$, and $\Delta v$ is a velocity error corresponding to length-scale error $\Delta X$. The actual video velocity $v$ can then be obtained as

$$
v=\frac{X_{\text {grid }}-\Delta X}{\Delta t}=\frac{C X_{\text {grid }}}{\Delta t}=C v_{\text {grid }}
$$

where $C=1$ indicates no grid distortion, and increasing grid error is indicated as $C$ departs from 1.

\section{Ice breakup-March 1993}

A 30-minute Doppler radar ice velocity record and a simultaneous video ice velocity record were obtained for the Connecticut River at the Cornish-Windsor bridge on 30 March 1993. Specifications that characterize the radar system used are given in Table 1 . The radar antenna was mounted about $6 \mathrm{~m}$ above the ice and aimed directly upstream with an angle $\beta$ of $25^{\circ}$ below horizontal. Concurrently, a video camera was mounted at the top of the left bank and aimed normal to the direction of the flow. The streamline where video data were obtained passed through the footprint of the radar. Ice breakup
Table 1. Doppler system configurations.

\begin{tabular}{lll} 
& \multicolumn{2}{c}{ Event } \\
\cline { 2 - 3 } & Breakup & Frazil run \\
\hline Radar band & $\mathrm{C}$ & Ka \\
Frequency & $5 \mathrm{GHz}$ & $30 \mathrm{GHz}$ \\
Wavelength & $6 \mathrm{~cm}$ & $1 \mathrm{~cm}$ \\
Antenna gain & $15 \mathrm{~dB}$ & $27 \mathrm{~dB}$ \\
$3 \mathrm{~dB}$ antenna beam width & $20^{\circ}$ & $9^{\circ}$ \\
Microwave power & $20 \mathrm{dBm}$ & $20 \mathrm{dBm}$ \\
\hline
\end{tabular}

was underway at a river flow of approximately $850 \mathrm{~m}^{3} / \mathrm{s}$ when measurements began. For most of this record, the ice was densely packed rubble that provided strong radar reflections and many video targets. Toward the end of the sampling period, the surface ice concentration diminished and the ice velocity increased.

The ice velocity-time trace obtained from the Doppler frequency band is presented in Figure 7. Digital signal processing software identified the peak return from each radar scan in this record. These peak detector data, representing the highest magnitude power reflections from within the footprint illuminated by the radar, are also plotted in Figure 7 . Both of these data sets were processed by first identifying the upper $v_{+}$and lower $v_{-}$edges of the trace at 20- or 30-s intervals throughout the record; the results are shown in Figure 7 . The peak returns generally originated

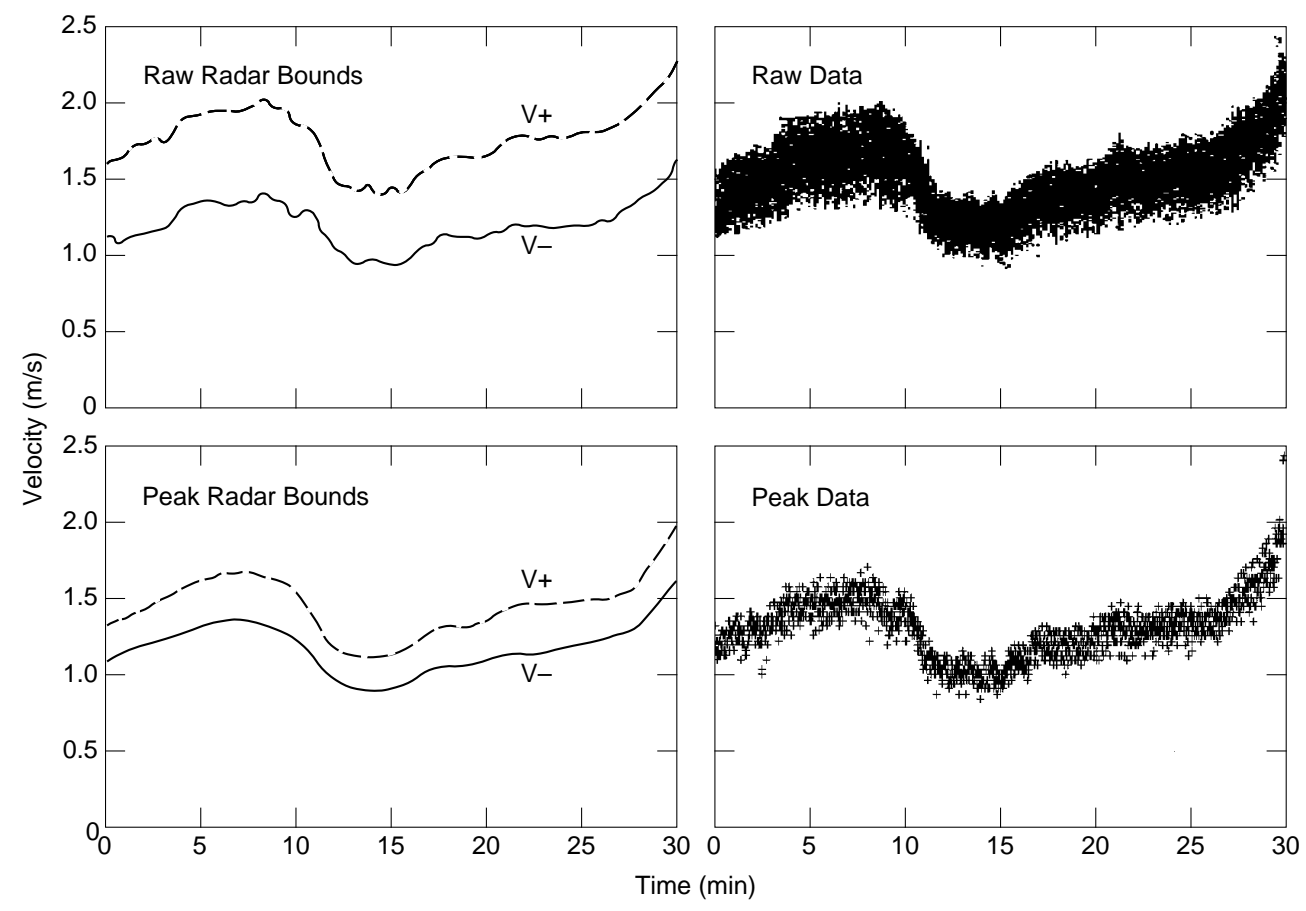

Figure 7. Data band of raw Doppler velocities and peak returns for the ice breakup event and boundaries that were drawn for each of these data sets. 


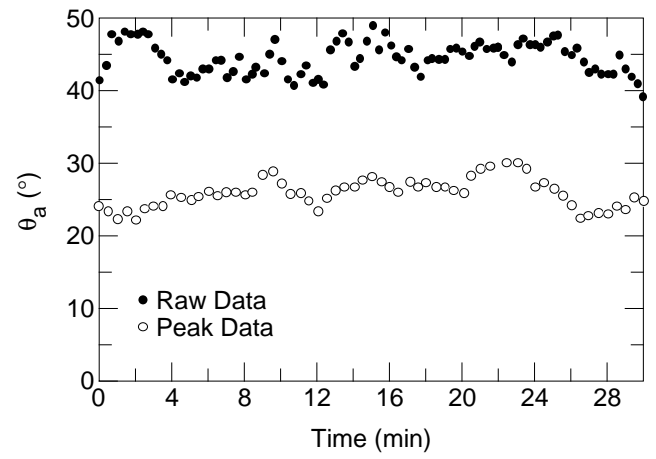

Figure 8. Calculated $\theta_{a}$ as a function of time for the raw and peak radar data records for the breakup event. These values result from an equal boresight velocity requirement for the near and far edge traces.

close to the near edge of the footprint, consistent with the inverse relationship between backscattered power and range to the fourth power given in eq 1.

Using eq 11 we calculated $\theta_{a}$ for both the raw and peak detector data records; we present the respective results in Figure 8 as a function of time. For the raw data record the mean, median, and mode of $\theta_{\mathrm{a}}$ are approximately equal, with a mean of $44.6^{\circ}$, a standard deviation of $2.2^{\circ}$, and a range of $10.0^{\circ}$. The mean, median, and mode of $\theta_{\mathrm{a}}$ for the peak data record are also approximately equal, with a mean of $26.0^{\circ}$, a standard deviation of $2.1^{\circ}$, and a range of $9.4^{\circ}$. The peak-finding algorithm significantly reduced the apparent beam width of the radar without altering the $\theta_{a}$

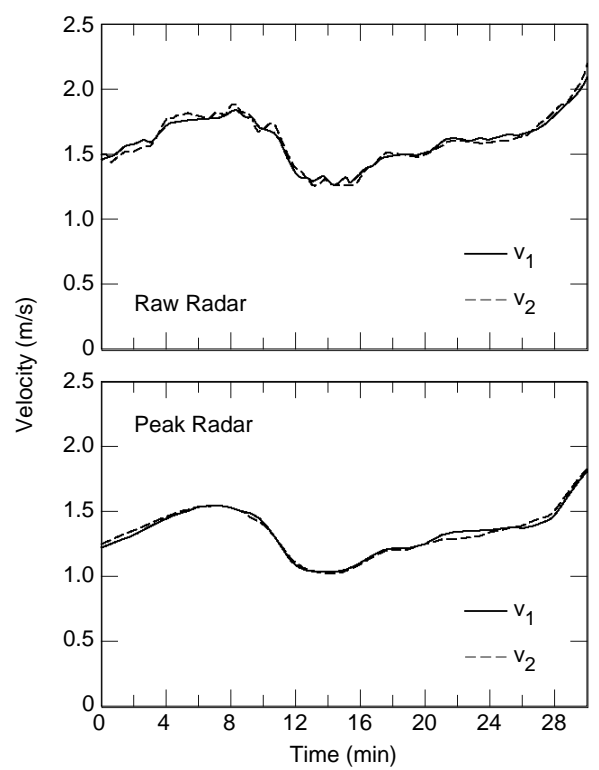

distribution. The $v_{1}$ and $v_{2}$ results and the difference between these values nondimensionalized by the corresponding mean velocity are given in Figure 9. Except for a few points, the absolute value of this dimensionless difference was less than 0.04 in both records, corresponding to an absolute value of the difference between $v$ and either $v_{1}$ or $v_{2}$ of less than $0.02 v$. The delineation of the limits of each radar trace and calculation of a mean $\theta$ has reduced the large potential beamwidth error to the same order as the other minor errors inherent in Doppler velocity measurement. The peak data are smooth relative to the raw data, but they are shifted systematically to lower velocities, following the downward shift of the far edge of the trace. The resulting mean velocity of the peak radar record is $1.35 \mathrm{~m} / \mathrm{s}$, and that of the raw radar record is $1.61 \mathrm{~m} / \mathrm{s}$.

The velocity data from the video record are shown with the selected polynomial fit and the corresponding normalized error in Figure 10. The mean and median of the normalized error were very close to zero, with a standard deviation of 0.026 . The maximum normalized error of about $0.06 v$ is within the measurement error bound for this method (Ferrick et al. 1992). Comparison of the radar and video velocities reveals that the video results are consistently low. For ease of comparison we assume that this systematic difference is due entirely to video grid distortion. We obtain $C$ in eq 14 from the ratio of the raw radar to video polynomial mean velocity values as 1.067 .

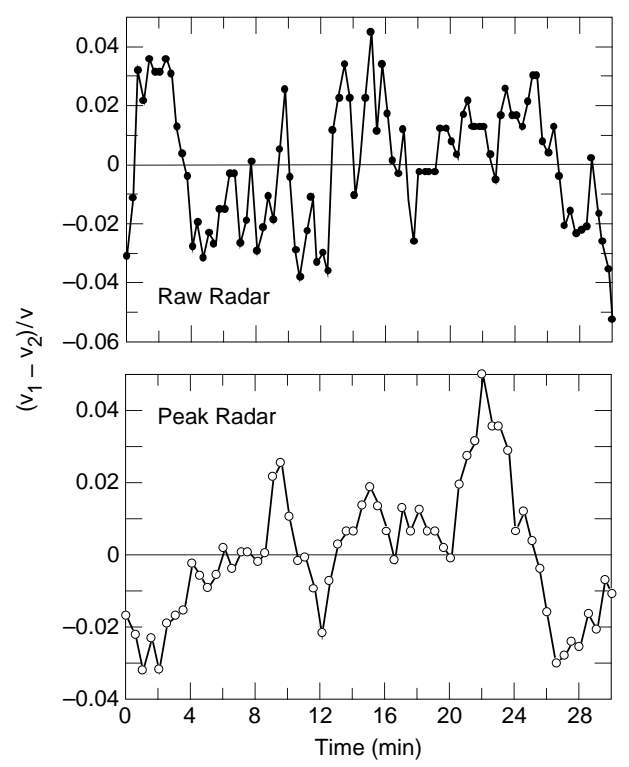

Figure 9. Ice breakup boresight velocities and their normalized difference obtained from the edge traces, with the corresponding mean $\theta_{a}$ of both the raw and peak radar data records. 

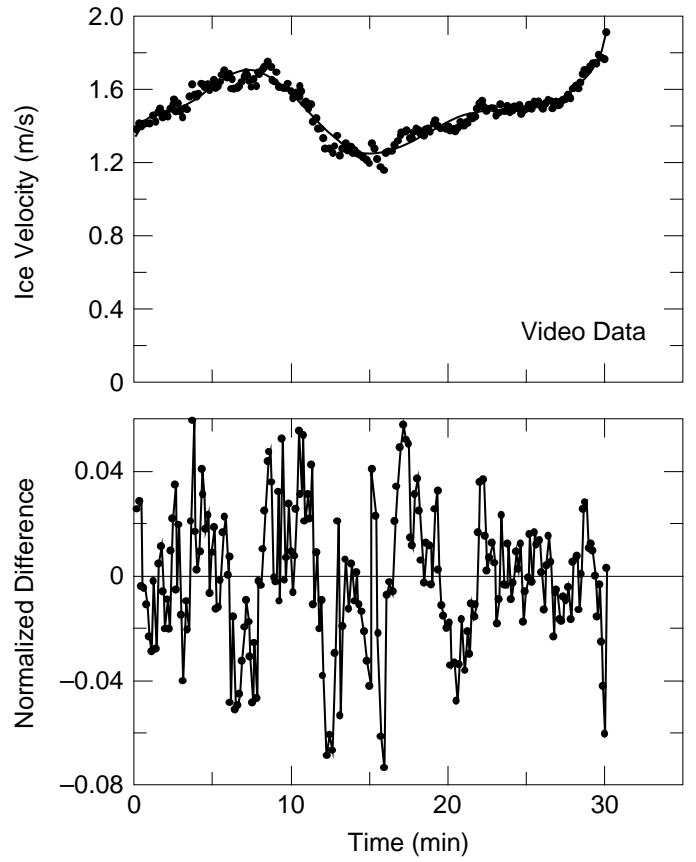

Figure 10. Ice velocity data, best polynomial fit, and normalized difference between the data and polynomial of the video ice breakup record.

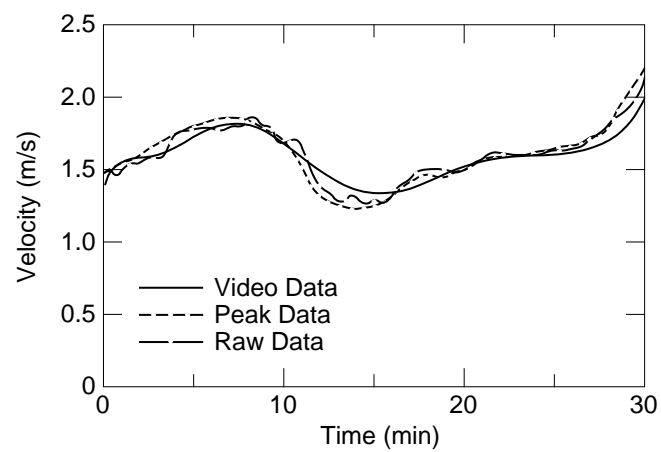

Figure 11. Comparison of ice velocity results for breakup after multiplying the video and peak radar results by a constant that equates the mean velocity of each record.

Almost identical correlation coefficients were obtained for all pairs of the raw radar, peak radar, and polynomial video velocity records, ranging between 0.933 and 0.950 . The ice velocity-time traces obtained with each method are superposed in Figure 11, following multiplication of the peak return results by 1.191 and the video polynomial results by 1.067 to correct for the mean offset from the raw radar results. The root-mean-square (RMS) difference obtained between any pair of records was less than $7.7 \mathrm{~cm} / \mathrm{s}$, corresponding to dimensionless RMS velocity differences of 0.033 , 0.037 , and 0.048 between the video-raw, video- peak, and raw-peak records, respectively. Given the various measurement errors, these comparisons suggest fundamental agreement of the methods. However, additional development of the peak return data reduction method is needed because of the significant underprediction of the mean velocity.

Ice velocities exceeding $5 \mathrm{~m} / \mathrm{s}$ during breakup have been reported on some rivers. The maximum Doppler frequency that can be obtained with a given system is limited by the Nyquist sampling rate, $f_{\mathrm{d}} \leq N / 2$. With our system, velocities of up to $6 \mathrm{~m} / \mathrm{s}$ can be obtained with Doppler frequencies less than $200 \mathrm{~Hz}$, indicating that the Nyquist rate does not restrict velocity measurement at the high end of the observed range. Unlike optical methods, the large changes in river stage that can occur during breakup do not affect Doppler radar velocity measurement.

\section{Frazil ice run-December 1993}

Doppler radar ice velocity and simultaneous video ice velocity records were obtained for the Connecticut River at the Cornish-Windsor bridge on 28 December 1993. Frazil pans and floes were moving downstream during the measurement period at a river flow of about 170 $\mathrm{m}^{3} / \mathrm{s}$, just prior to ice cover formation. Over several hours of data collection, the river flow and ice velocity conditions were relatively steady, and we selected a typical 1000-s record for analysis. The video setup and grid were the same as in the previous event. The radar antenna was mounted at the same height and location as before, about $11 \mathrm{~m}$ above the lower water surface. To reduce the data processing requirements of the method, an antenna with a much narrower beam width was used. With slower ice motion expected, the wavelength of the radar was decreased to improve the velocity resolution. Using eq 2, the Doppler frequency shift needed to resolve velocity differences of $0.05 \mathrm{~m} / \mathrm{s}$ is only 1.5 $\mathrm{Hz}$ for a $5-\mathrm{GHz}$ microwave source. The corresponding frequency shift increases to $9 \mathrm{~Hz}$ with a 30-GHz millimeter-wave source. A millimeterwave source provides sufficient resolution for ice velocity measurement at speeds above about 0.1 $\mathrm{m} / \mathrm{s}$. The modified radar system specifications are given in Table 1.

The video velocity data, best fifth-order polynomial fit, and difference between the data and the polynomial normalized by the polynomial velocity are given in Figure 12. The mean video velocity was $0.518 \mathrm{~m} / \mathrm{s}$, and the normalized dif- 

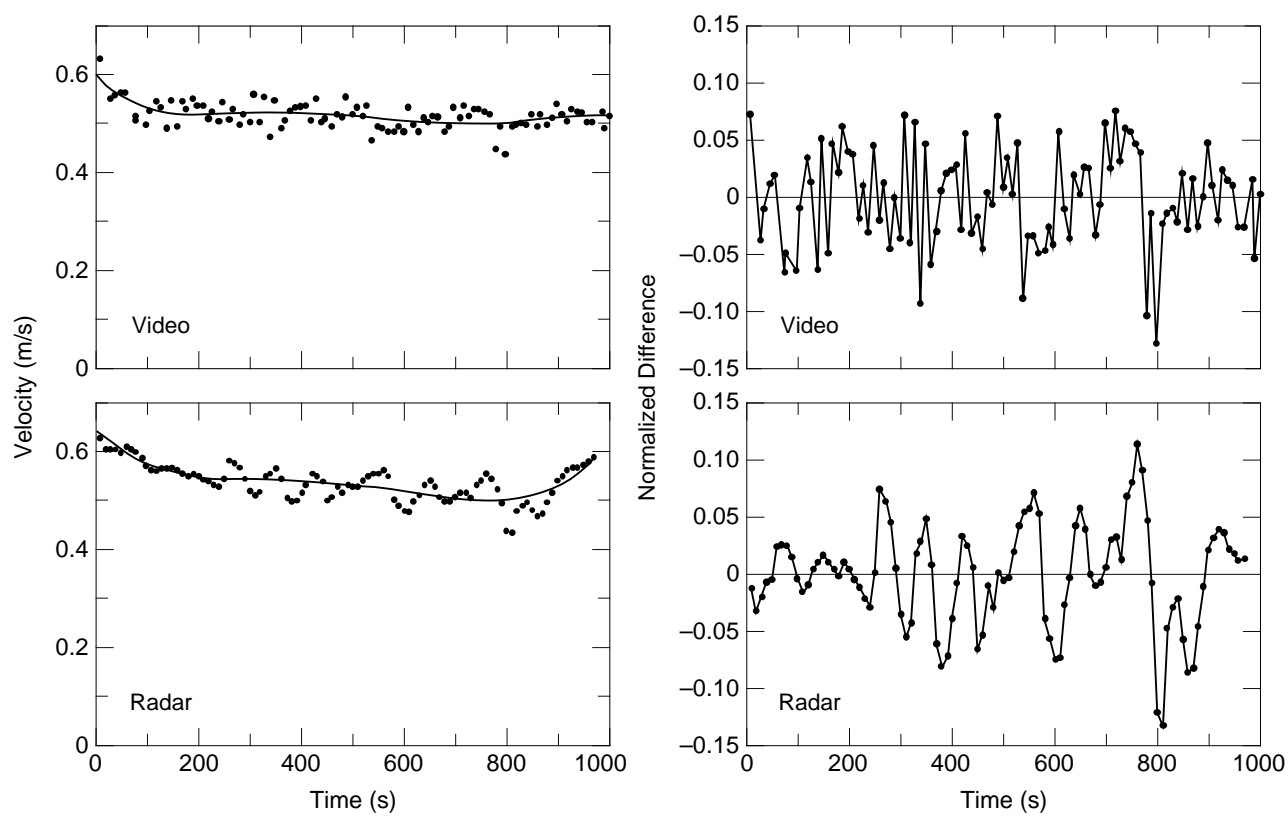

Figure 12. Video and radar data, best polynomial fits, and normalized difference between the data and corresponding polynomial for the frazil ice run.

ference between the data and the polynomial was generally less than 0.06 . The mean and median difference are both zero, with an RMS difference of $0.022 \mathrm{~m} / \mathrm{s}$ and a maximum difference of 0.065 $\mathrm{m} / \mathrm{s}$. The amplitudes of the velocity differences are within the bounds of experimental error, and their structure is random. We conclude that the polynomial adequately describes the video data.

The full width of the Doppler frequency band was a difference in velocity of $0.05 \mathrm{~m} / \mathrm{s}$, or a normalized velocity difference of 0.09 . Data representing the midpoint of the band obtained at 10-s intervals, the best fourth-order polynomial fit to these data, and the normalized difference between the data and the polynomial are presented in Figure 12. The mean radar velocity was 0.539 $\mathrm{m} / \mathrm{s}$, and the normalized difference was generally less than 0.07. The mean and median differences are both zero, with an RMS difference of $0.023 \mathrm{~m} / \mathrm{s}$ and a maximum difference of $0.067 \mathrm{~m} / \mathrm{s}$. The amplitudes of the velocity differences are somewhat larger than would be expected from experimental error, and their structure appears periodic. However, the oscillations in this record are not supported by the video data. The oscillating radar velocities occurred when the open water area in the radar footprint increased and the number of targets decreased. When a single floe traverses the footprint there is an apparent change in velocity from high to low caused by the relationship between vertical angle and Doppler frequency. Figure 13 shows part of the breakup

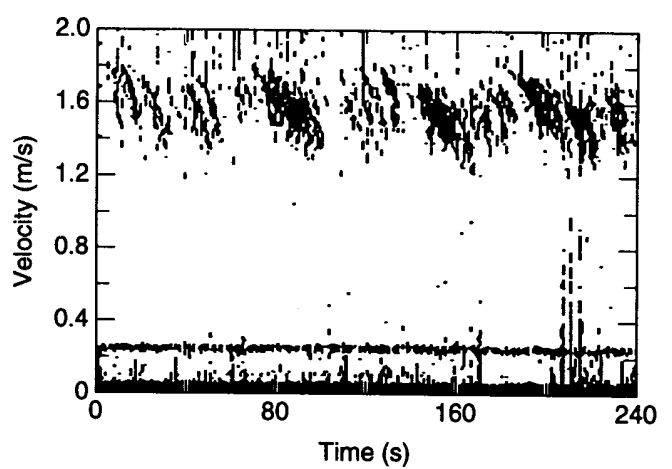

Figure 13. The part of the radar velocity record for breakup with dispersed ice floes in the river. Note the movement in time of strong returns from higher to lower velocity, corresponding to the movement of floes through the antenna footprint.

record during the period of dispersed ice motion. Bands of velocity through time from floes producing strong backscatter are clearly visible.

Small underestimates of $\alpha$ and $\beta$ would cause a systematically high radar velocity, corresponding to most of the difference between the Doppler and video mean velocities. In addition, strong individual reflectors that passed through the radar footprint at constant speed spent almost $60 \%$ of this time on the high-velocity side of the boresight, potentially introducing a velocity bias. However, for consistency and ease of comparison we again assume that the systematic difference between the radar and video velocities is due to video grid distortion. The video and radar veloc- 


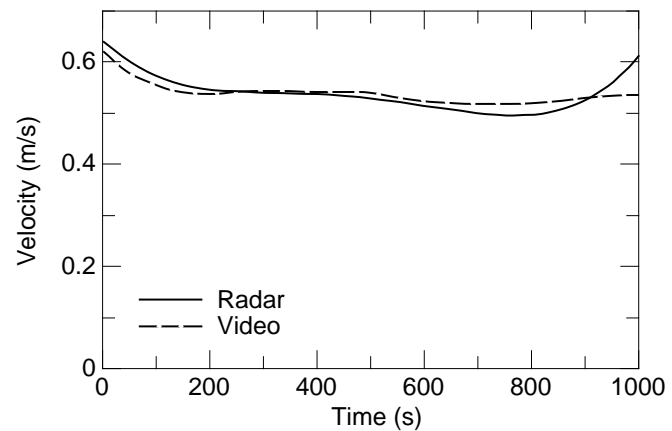

Figure 14. Comparison of ice velocity results for the frazil run after the video results are multiplied by a constant that equates the mean velocity of each record.

ity polynomials are compared in Figure 14 after the video velocity polynomial is multiplied by 1.041 to correct for the difference in the means. Discounting the tail of the radar polynomial that is an end-effect of the final oscillation, the RMS difference between these curves is $0.014 \mathrm{~m} / \mathrm{s}$, or 0.026 when normalized by the mean velocity. Except for the oscillations induced by strong and sparse reflectors, the Doppler radar and video data agreement is well within the measurement errors of the methods. The Doppler radar system again provided an excellent velocity measurement with minimal processing.

\section{CONCLUSIONS}

Doppler ice velocity measurements are made remotely, can be displayed in real time, and are not affected by light, fog, or ice motion conditions. Doppler radar can measure and resolve the velocity of ice moving in a river with precision comparable to or better than analysis-intensive video techniques, over the complete range of ice and velocity conditions. The maximum error in Doppler radar measurement of river ice motion is about $5 \%$ of the velocity. Agreement between the mean Doppler and video velocities was obtained within $7 \%$ for the ice breakup case study and $4 \%$ for the frazil run. Video grid distortion during breakup and sparse radar targets during the frazil run are likely causes of these systematic differences in velocity. The RMS differences between the meancorrected velocity curves were about $3 \%$ for both cases. A high gain, narrow-beam antenna improved signal-to-noise performance of our Doppler radar system and minimized data processing requirements. An increase in the source frequency of the system provided a proportional increase in the velocity resolution.

Significant cost reduction and miniaturization can now be realized through application of offthe-shelf $10-\mathrm{GHz}$ and $24-\mathrm{GHz}$ microwave transceiver modules consisting of a horn antenna, circulator, diode mixer, and Gunn oscillator. These modules only require connections to dc power and to a data acquisition computer to realize a Doppler radar system, encouraging long-term or permanent mounting of sensors at strategic points on a river to provide early warning and continuous monitoring of ice freeze-up or breakup. A laptop computer equipped with a PCMCIA data acquisition card enhances system portability and reduces power requirements.

\section{LITERATURE CITED}

Arcone, S.A. (1991) Dielectric constant and layer thickness interpretation of helicopter-borne shortpulse radar waveforms reflected from wet and dry river-ice sheets, IEEE TGARS, 29: 768-777.

Arcone, S.A. and A.J. Delaney (1987) Helicopterborne short-pulse radar profiles of river-ice sheets in Alaska. Journal of Glaciology, 97: 333-341.

Barton, D.K. (1964) Radar System Analysis. New York: Prentice-Hall.

Ferrick, M.G., P.B. Weyrick and S.T. Hunnewell (1992) Analysis of river ice motion near a breaking front. Canadian Journal of Civil Engineering, 19: 105116.

Ferrick, M.G., P.B. Weyrick and D.F. Nelson (1993) A kinematic model of river ice motion during dynamic breakup. Nordic Hydrology, 24: 111-134.

Lewis, E.O., B.W. Currie and S.Haykin (1987) Detection and Classification of Ice. New York: John Wiley and Sons.

Prowse, T.D. and M.N.Demuth (1991) Measurement of freeze-up and break-up ice velocities. In Proceedings of the 48th Eastern Snow Conference, Guelph, Ontario, 5-7 June, p. 325-331.

Roddy, D. (1984) Microwave Technology. New York: Prentice-Hall.

Skolnik, M.I. (1980) Introduction to Radar Systems. New York: McGraw-Hill.

Yankielun, N.E. and M.G. Ferrick (1993) Automatic, continuous river stage measurement with a millimeter-wave FM-CW radar. USA Cold Regions Research and Engineering Laboratory, CRREL Report 93-24.

Yankielun, N.E., S.A. Arcone and R.K. Crane (1992) Thickness profiling of freshwater ice using a millimeter-wave FM-CW radar. IEEE Transactions on Geoscience and Remote Sensing, 80: 1094-1100.

Yankielun, N.E., M.G. Ferrick and P.B. Weyrick (1993) Development of an airborne millimeterwave FM-CW radar for mapping river ice. Canadian Journal of Civil Engineering, 20: 1057-1064. 


\begin{tabular}{|c|c|c|}
\hline $\begin{array}{l}\text { Public reporting burden for this collection of in } \\
\text { maintaining the data needed, and completing } \\
\text { including suggestion for reducing this burden, } \\
\text { VA 22202-4302, and to the Office of Managen }\end{array}$ & $\begin{array}{l}\text { estimated to average } 1 \text { hour per respon } \\
\text { ig the collection of information. Send co } \\
\text { ton Headquarters Services, Directorate } \\
\text { dget, Paperwork Reduction Project (070 }\end{array}$ & $\begin{array}{l}\text { time for reviewing instructions, searching existing data sources, } \\
\text { ng this burden estimate or any other aspect of this collection of int } \\
\text { perations and Reports, } 1215 \text { Jefferson Davis Highway, Suite } 120 \\
\text { ngton, DC } 20503 \text {. }\end{array}$ \\
\hline 1. AGENCY USE ONLY (Leave blank) & $\begin{array}{l}\text { 2. REPORT DATE } \\
\text { November } 1995\end{array}$ & 3. REPORT TYPE AND DATES COVERED \\
\hline $\begin{array}{l}\text { 4. TITLE AND SUBTITLE } \\
\text { A Doppler Radar for Cont } \\
\text { of River Ice Velocity }\end{array}$ & s Remote Measurement & $\begin{array}{l}\text { 5. FUNDING NUMBERS } \\
\text { PR: 4A762784AT42 } \\
\text { WU: } 001\end{array}$ \\
\hline $\begin{array}{l}\text { 6. AUTHORS } \\
\text { Michael G. Ferrick, Norbe }\end{array}$ & ankielun and David F. N & TA: CS \\
\hline $\begin{array}{l}\text { 7. PERFORMING ORGANIZATION NA } \\
\text { U.S. Army Cold Regions } \\
72 \text { Lyme Road } \\
\text { Hanover, New Hampshire }\end{array}$ & $\begin{array}{l}\text { ND ADDRESS(ES) } \\
\text { ch and Engineering Labo } \\
5-1290\end{array}$ & $\begin{array}{l}\text { 8. PERFORMING ORGANIZATION } \\
\text { REPORT NUMBER } \\
\text { CRREL Report 95-21 }\end{array}$ \\
\hline $\begin{array}{l}\text { 9. SPONSORING/MONITORING AGEN } \\
\text { Office of the Chief of Engi } \\
\text { Washington, DC 20314-10 }\end{array}$ & AE(S) AND ADDRESS(ES) & $\begin{array}{l}\text { 10. SPONSORING/MONITORING } \\
\text { AGENCY REPORT NUMBER }\end{array}$ \\
\hline
\end{tabular}

11. SUPPLEMENTARY NOTES

For conversion of SI units to non-SI units of measurement consult Standard Practice for Use of the International System of Units (SI), ASTM Standard E380-93, published by the American Society for Testing and Materials, 1916 Race St., Philadelphia, Pa. 19103.

12a. DISTRIBUTION/AVAILABILITY STATEMENT 12b. DISTRIBUTION CODE

Approved for public release; distribution is unlimited.

Available from NTIS, Springfield, Virginia 22161.

13. ABSTRACT (Maximum 200 words)

River ice velocity measurements are fundamental to analyses of river ice dynamics. Ice velocity measurement with a continuous-wave Doppler radar system having real-time data acquisition and digital signal processing capability was evaluated during a river breakup and a frazil run on the Connecticut River. This system can be rapidly deployed, requires minimal operator interaction, will continuously acquire, process, store, and display ice velocity data and does not depend on visibility conditions. In parallel, video records of ice motion were obtained at the same location for later manual processing and comparison with the radar results. We describe the Doppler radar system and obtain bounding estimates of possible measurement errors. The principal error in Doppler ice velocity measurement is due to the beam width of the radar antenna, and an analytical method is developed to minimize this error. Measured ice velocities ranged from 1 to $2.5 \mathrm{~m} / \mathrm{s}$ during the river breakup and from 0.5 to $0.65 \mathrm{~m} / \mathrm{s}$ in the frazil run. Quantitative comparisons between the radar and video results show fundamental agreement between these measurement methods and demonstrate that Doppler radar is an effective, efficient, and precise tool for obtaining river ice velocities over the full range of possible ice and velocity conditions.

\begin{tabular}{|c|c|c|c|}
\hline \multirow{2}{*}{$\begin{array}{l}\text { 14. SUBJECT TERMS } \\
\text { Doppler radar } \\
\text { River ice } \\
\text { Ice movement }\end{array}$} & \multirow{2}{*}{$\begin{array}{l}\text { Radar } \\
\text { Velocity }\end{array}$} & & \begin{tabular}{|c} 
15. NUMBER OF PAGES \\
17 \\
\end{tabular} \\
\hline & & & 16. PRICE CODE \\
\hline UNCLASSIFIED & UNCLASSIFIED & UNCLASSIFIED & UL \\
\hline
\end{tabular}

